\title{
Climate Variability and Dengue Hemorrhagic Fever in Surabaya, East Java, Indonesia
}

\author{
Sandra Choi Ning Tang ${ }^{1}$, Musofa Rusli ${ }^{2}$, Pudji Lestari ${ }^{3}$ \\ ${ }^{1}$ Faculty of Medicine, Universitas Airlangga, 60131 Surabaya, Indonesia; san.tang.choi-2015@fk.unair.ac.id \\ ${ }^{2}$ Department of Internal Medicine, Universitas Airlangga, Dr.Soetomo Hospital, 60131 Surabaya, Indonesia; \\ musofa-r@fk.unair.ac.id \\ ${ }^{3}$ Department of Public Health, Faculty of Medicine, Universitas Airlangga, 60131 Surabaya, Indonesia; \\ pudjilestari70@fk.unair.ac.id
}

\begin{abstract}
Dengue hemorrhagic fever is an arboviral infectious disease that has occurred frequently as an extraordinary event due to its fast spread and lethal potential in Indonesia. The vector Aedes aegypti is sensitive to climate variability. This study determines the relationship between climate variability and dengue hemorrhagic fever in Surabaya, East Java, Indonesia from 2009 to 2017. This study used the monthly dengue hemorrhagic fever incidence obtained from the Surabaya Health Office and the monthly climate variability parameters (average temperature, rainfall, humidity) obtained from the Indonesian Agency for Meteorology, Climatology and Geophysics and website www.worldweatheronline.com. Data analysis was done using One-Sample Kolmogorov Smirnov Test and Spearman non-parametric correlation test. The results showed a correlation between all three climate variability parameters with dengue hemorrhagic fever incidence (average temperature $\mathrm{p}<0.05, \mathrm{r}=-0.603$; rainfall $\mathrm{p}<0.05, \mathrm{r}=0.407$; humidity $\mathrm{p}<0.05, \mathrm{r}=0.7$ ). Average temperature is negatively correlated to dengue hemorrhagic fever incidence, while rainfall and humidity are positively correlated to dengue hemorrhagic fever incidence. This study shows preliminary evidence on the correlation of climate variability and dengue hemorrhagic fever in Surabaya, East Java, Indonesia.
\end{abstract}

Keywords: Climate variability; dengue hemorrhagic fever incidence; average temperature; humidity; rainfall; Surabaya

\section{Introduction}

Dengue fever (DF), an infectious disease, and its more severe manifestation dengue hemorrhagic fever (DHF) are the fastest emerging arboviral infectious disease in tropical and subtropical countries and have become a major public health concern globally. It is estimated 2.5 billion people are at risk of dengue infection, while an estimated 50 million dengue infections occur worldwide with 500 thousand people requiring hospitalization for DHF annually [1] .

DHF has occurred frequently as an extraordinary event due to its fast spread and fatal potential in Indonesia. The first reported cases of DHF in Indonesia occurred in Jakarta and Surabaya in 1968 [2]. The incidence rate has increased ever since with expanding endemic regions and has affected most of the provinces in East Java [3], [4]. Surabaya was recorded as the province with the highest DHF incidence rate in East Java back in 2012 [3], with very high coping range index (CRI) levels in 2007-2009 and 2011-2012 [5].

DF and DHF are caused by dengue viruses (DENV), which form the dengue complex in the genus Flavivirus, family Flaviviridae. This self-limited, systemic viral infection is caused by four antigenically related viruses (DENV 1-4) found circulating in the tropical and subtropical regions of the world [6], [7].

DHF is transmitted from a female mosquito to susceptible humans mainly by bites of the female Aedes aegypti and Aedes albopictus mosquito species. As a tropical country, Indonesia with a monsoonal wet season and a dry season provide an optimum habitat to support the breeding of Aedes aegypti mosquitoes and spread of its virulent infection [8]. The other factors that impact the increasing 
dengue disease burden are complex and consist of these key determinants: climatic factors, urbanization, increased global travel, geographical spread of dengue vectors, decay in public health infrastructures, lack of effective mosquito control, and the unprecedented global population growth [1], [9].

Climate variability plays an important role in the epidemiology of vector-borne diseases. It is one of the most important environmental factor that affects human health and the spread of diseases. It is a complex study that requires a thorough understanding of the links with the climate and disease [10]. Examples of the climatic variables included in climatic factors are qualitatively the temperature, humidity and rainfall [11], [12].

Existing literature sources have corroborated the association of humidity and temperature with the adult mortality rate and fecundity of vector populations. In these studies, the intensity of the temperature effect is strongly associated to humidity and it is reported that female vector populations can survive two-fold more and produce more eggs during rainy seasons at low temperature and at high relative humidity [13]. These studies suggest that temperature and humidity variations creates an effect on the fecundity, fertility and survival of vector populations, where a decreased vector population is correlated with the decreased temperature and increased humidity, with a negative effect on several aspects of mosquito biology [14]. However, a full understanding of the quantitative nature of these variables is still lacking and inconclusive. Further quantitative analysis needs to be done to understand dengue dynamics [15].

There is no specific treatment available to treat the virus. Currently, DHF is primarily treated by the control management of the mosquitoes. Meanwhile, the programs to combat and alleviate DHF burden in the South-East Asia region are not largely successful [1]. Recent findings also found an increasing trend for global dengue epidemic potential in temperate regions over time [16]. To combat the increasing burden of DHF cases, the various factors of dengue transmission need to be addressed to generate appropriate preventive and control measures.

Previous research has stated the potential impact of several climatic variables on spread of DHF but the impact of climatic data on the spread of dengue is still uncertain [17]. To date, there are only a few research studies [18] done on the effect of climatic variables on the spread of DHF in Surabaya. Therefore, the goal of this study is to investigate the effect of climatic data on dengue transmission in Surabaya in the hopes that it may assist in the planning of more effective vector control and DHF surveillance programs via weather forecasting networks in the future, in conjunction of preventing the endemicity of DHF in Surabaya.

\section{Materials and Methods}

Study Area: This study was conducted in Surabaya, an endemic area for Dengue Hemorrhagic Fever in Indonesia. It is situated between $112^{\circ} 36^{\prime \prime}$ and $112^{\circ} 54^{\prime \prime}$ longitude line and between $07^{\circ} 12^{\prime \prime} \mathrm{S}$ latitude line. Surabaya is a city area with $326.37 \mathrm{~km}^{2}$ and a human population of 2,862,406 million inhabitants. Surabaya consists of 31 sub-districts (kecamatan) and 154 administrative villages (kelurahan), and is the capital of the East Java province [19]. The sample size in this study are the Surabaya human population of 2,862,406 inhabitants.

Data Collection: The secondary data of DHF cases and climatic data were collected for this research. The monthly DHF case incidence data from 2009 to 2017 were obtained from the Surabaya City Health Office. These reported DHF cases were diagnosed using the standardized WHO clinical 
criteria. The monthly climatic data from 2009 to 2017 was collected from the online website www.worldweatheronline.com and the Indonesian Agency for Meteorology, Climatology and Geophysics. These monthly climatic data consisted of the monthly average temperature, rainfall and humidity. Initially, there was a restriction access to obtain the monthly DHF case incidence data from the Surabaya City Health Office. Assistance from co-author three who is in the Public Health Field was required to attain clearance to obtain the data. There was also a restriction access from the Indonesian Agency for Meteorology, Climatology and Geophysics to obtain climatic data. The maximum obtainable data was only for two years from 2016 to 2017. Nevertheless, full monthly climatic data was accessible from the online website www.worldweatheronline.com for the Surabaya region in Indonesia.

Statistical Analysis: SPSS statistical software package version 16.0 was used for the statistical analysis. The One-Sample Kolmogorov Smirnov Test was used to evaluate the cumulative distribution function for the data. The Spearman non-parametric correlation test was used to examine the relationship between monthly climatic data and DHF incidence. The Spearman's correlation coefficient is a statistical measure of the strength of the relationship between the paired data. When the correlation coefficient value is closer to \pm 1 , the stronger the relationship between the paired data.

\section{Results}

\subsection{Profile of Dengue Hemorrhagic Fever Incidence from 2009 to 2017 in Surabaya, Indonesia}

During the study period from 2009 to 2017, a total of 12,672 dengue hemorrhagic fever (DHF) cases were diagnosed and reported (Figure 1 (a)). The figure illustrated the annual total DHF cases from 2009 to 2017, showing a "downslope" trend with sudden "spikes" in between. The highest total DHF cases were recorded in 2010 (3379 cases, IR of 116 per 100,000 person-years), and the lowest total DHF cases were recorded in 2017 (325 cases, IR of 11.3 per 100,000 person-years). Between 2010 to 2017, the total DHF cases and IR incidence rate (Figure 1 (b)) had sudden increases in 2013 and 2016.

Despite the overall decreasing DHF cases from 2009 to 2017, the case fatality rate (CFR) of DHF cases illustrated an increasing pattern. The CFR was the highest in 2014 (2.1) and the lowest in 2009 (0.3). Figure 1 (c) illustrated the case fatality rate (CFR) of DHF cases.

When the total DHF cases (Figure 1 (d)) were illustrated based on months from 2009 to 2017, the fluctuation of the DHF cases was shown to correspond to the seasonality patterns of the months in a year in Surabaya, Indonesia. Overall, the figure showed the DHF cases recorded were highest from March to May and were the lowest in September.

The time series charts (Figure 1 (e); (f) \& (g)) illustrated the trends of the monthly DHF cases and monthly climatic data. The monthly DHF cases fluctuated similarly to the monthly rainfall trends in Figure 1 (f) and the monthly humidity in Figure 1 (g), while the monthly average temperature had a low thermal variation of less than 10 degree Celsius in Figure 1 (e). 


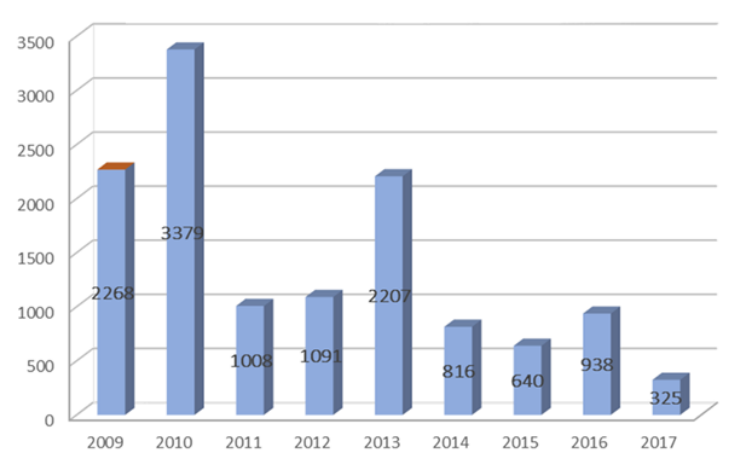

(a)

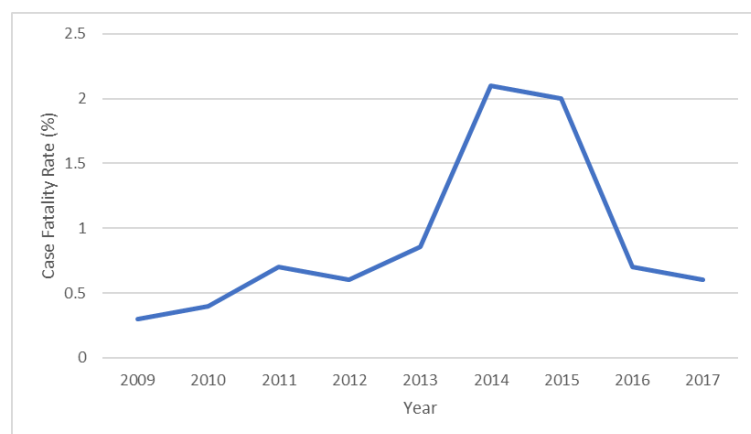

(c)

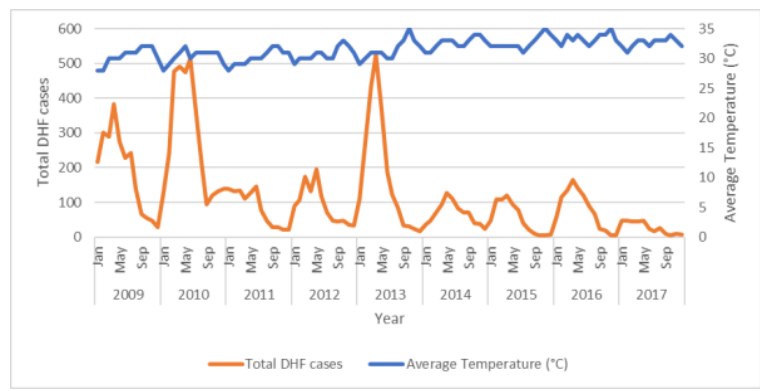

(e)

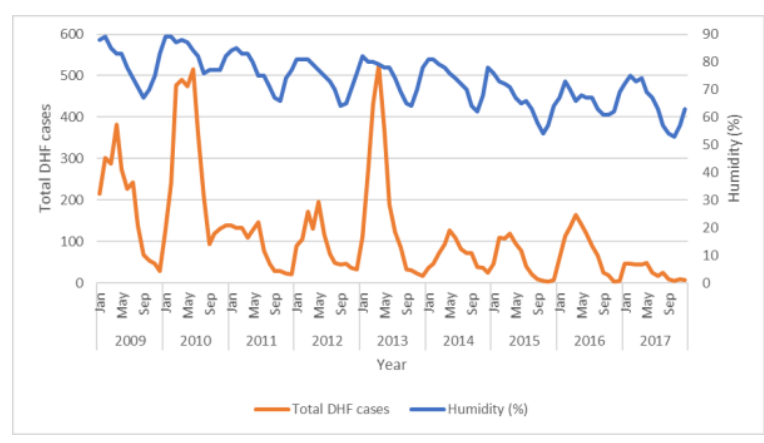

(g)

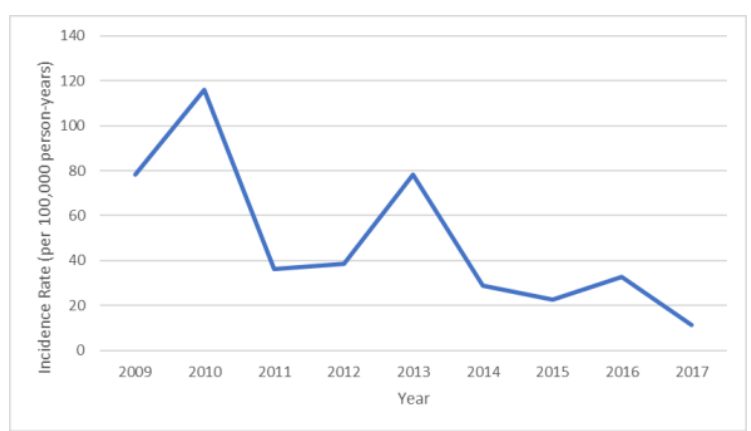

(b)

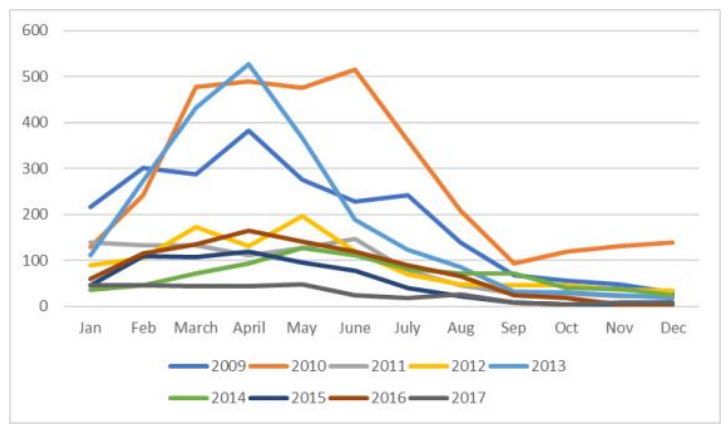

(d)

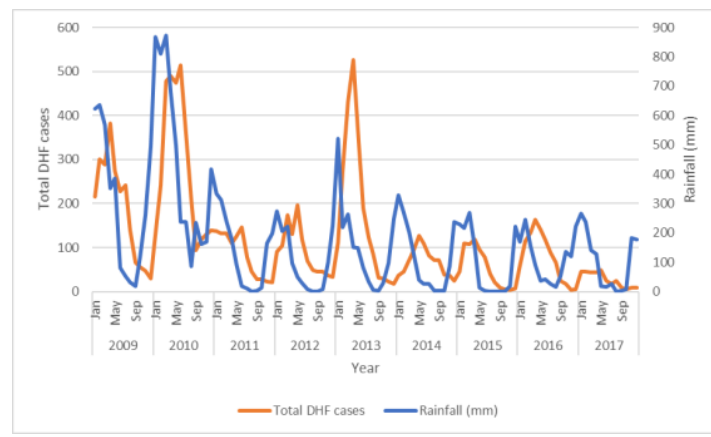

(f)

Figure 1. Profile of DHF cases from 2009 to 2017 in Surabaya, Indonesia (a) Annual total DHF cases (b) Incidence rate (IR) of DHF cases (c) Case fatality rate (CFR) of DHF cases (d) Monthly total DHF cases (e) Monthly average temperature and monthly DHF cases (f) Monthly rainfall and monthly DHF cases (g) Monthly humidity and monthly DHF cases

\subsection{Relationship between Climate Variability and Dengue Hemorrhagic Fever}

The One-Sample Kolmogorov Smirnov Test showed that the monthly average temperature, monthly rainfall, monthly humidity and monthly total DHF cases from 2009 to 2017 were not in normal distribution ( $\mathrm{p}$-value $=0.000$, which is lesser than 0.05 for both variables). Therefore, the Spearman non-parametric correlation test was used to identify the relationship between both variables. 
The results showed a negative correlation $(\mathrm{r}=-0.603)$ between the monthly average temperature and monthly total DHF cases with a positive significance $(p=0.01)$. Therefore, there was a significant correlation between average temperature and DHF incidence. The negative correlation denotes that when the average temperature increases, the DHF incidence decreases; and vice versa.

The results showed a positive correlation $(\mathrm{r}=+0.407)$ between the monthly rainfall and monthly total DHF cases with a positive significance $(p=0.01)$. Therefore, there was a significant positive correlation between rainfall and DHF incidence. The positive correlation denotes that when the rainfall increases, DHF incidence increases; when the rainfall decreases, DHF incidence decreases.

The results showed a positive correlation $(r=+0.700)$ between the monthly average humidity and monthly total DHF cases with a positive significance $(p=0.01)$. Therefore, there was a significant positive correlation between humidity and DHF incidence. The positive correlation denotes that when humidity increases, DHF incidence increases; when humidity decreases, DHF incidence decreases.

\section{Discussion}

\subsection{Profile of Dengue Hemorrhagic Fever Incidence from 2009 to 2017 in Surabaya, Indonesia}

\subsubsection{DHF Incidence and Case Fatality Rate}

It is difficult to say whether the DHF case profile in Surabaya from 2009 to 2017 has improved compared to previous decades due to the fluctuating trend pattern of DHF cases over the past 50 years [2]. Ever since the first outbreak of DHF back in 1968 that occurred in Surabaya and Jakarta, DHF has become more widespread geographically in Indonesia [2]. By 1985, the disease has spread to 26 of 27 provinces from the 2 provinces in 1968 [20]. After 20 years from the first recorded DHF outbreak, in 1988, the CFR increased to 27.1 per 100,000 population in Indonesia [21]. Specific measures and efforts were taken by the Indonesian government and public health officials to mitigate the DHF incidence. By 1989, the DHF incidence has decreased to a low 6.1 per 100,000 population. However, ever since 1989, DHF incidence fluctuated and experienced a vast increase from 1994 to 1998, with 1998 having the highest IR (35.19 per 100,000 population) recorded, until its record was broken with an IR of 35.4 per 100,000 population in 2004 [21], [22].

The "down sloping" trend of DHF incidence in recent years could be due to the effective surveillance and vector control programs carried out by the Surabaya City health officials. The Indonesian government put high importance on surveillance efforts and vector control programs to counter dengue transmission [22]. Thermal fogging, mass larviciding, insecticides, and health awareness programs were reasonably successful in eradicating vector breeding sites and instilling awareness in the mass population about dengue transmission [21]. When mass larviciding coverage was considered inadequate (limited to $30 \%$ to $40 \%$ of endemic areas), communities organized efforts to promote "Pemberantasan Sarang Nyamuk (PSN 3M Plus)" which are the "menutup"- covering water containers, "menguras"- cleaning water containers and "mengubur"- burying discarded containers [22].

However, there were intermittent spikes of DHF incidence and increased CFRs over the study period which posed as a major problem in Surabaya. This observation differed with the CFR of the whole of Indonesia which were decreasing steadily over the past 50 years with the lowest rate at $1.21 \%$ in 2004 [2]. However, there were many factors underlying dengue virus transmission and this caused a difficulty in determining which specifically has caused complications in the eradication of Aedes 
mosquitoes. The lack of awareness in the society and the low community participation in mosquito eradication efforts may have affected the vector control efforts implemented by the Indonesian government, while human behavior in the community which has not adhered to healthy living may have also increased their susceptibility towards dengue infection [23]. Evidence had stated that ubiquitous efforts have been made in mosquito-control regimes by the Indonesian government, however the effectivity depended on the combined efforts and awareness of the community as dengue death tolls increased in Indonesia [24].

Our findings also showed that DHF incidence fluctuated according to the seasonality patterns of Indonesia. There was a marked increase of DHF incidence towards the end of the rainy season (December to March), and a decrease of DHF incidence during the dry season (June to September). This was supported by the complex dynamics of climatic influence on the ecology and the interaction with increased vector density after rainy seasons in tropical countries [12].

The marked increase of DHF incidence could also occur due to regional climate phenomenon El Niño Southern Oscillation (ENSO). Several studies found associations between ENSO events and increased DHF incidence [25], [26]. The 1998 increased DHF incidence in Surabaya and Jakarta may be due to ENSO [21]. This is because ENSO can influence climate variability, alter global rainfall patterns and modulate global temperatures [27].

During the spike of DHF incidence in 2010, 2013 and 2016 in Surabaya, there was unusual activity recorded in the ENSO phases at the Pacific Ocean. Significant La Niña events has occurred in 2010-2011 and 2011-12 which lead to record rainfalls and flooding in several countries [28]-[30]. This increased the risk of vector-borne disease outbreaks when flooding recedes. El Niño in 20152016 also presented potential bio-physical impacts in Indonesia, Brazil and Australia which lead to high risk of droughts in the developing phase and flooding during the decaying phase [31]. Droughts associated with increased water collection behavior and elevated temperatures increased the number of potential breeding sites for Aedes mosquitoes [32].

ENSO variations also impacted the tropical mean climate state and caused a consequential warming of the eastern tropical Pacific due to change in the global atmospheric circulation [33], [34]. The higher temperature led to higher transmission probability of dengue virus[35].

The results for the Surabaya DHF incidence trend in this study differed from other tropical countries in SEA region. Most countries in SEA experienced an increased IR and CFR of DHF cases [36]-[39], with Singapore and Malaysia having a decreased CFR despite the increasing IR over recent years. This could be due to the recent implementation of active surveillance programs for dengue in these countries that aimed to predict epidemic activity in advance of peak transmission [40]. Mexico and Brazil which has subtropical climates also had a similar trend pattern with tropical countries, with increasing IR of DHF cases in recent years [41], [42].

\subsubsection{Time Series Climatic Data and Dengue Hemorrhagic Fever}

The time series climatic data in Figure 1 (e), (f) and (g) showed a seasonality trend pattern for the climatic parameters which were the average temperature, humidity and rainfall and DHF incidence in Surabaya from 2009 to 2017. The results showed that the rainfall trend pattern was almost similar to the trend pattern of DHF incidence in Surabaya. Therefore, rainfall and DHF incidence were more likely to have a substantial relationship in Surabaya. Previous studies have found that dengue transmission was more likely to occur due to increased rainfall which formed more breeding habitats leading to increased vector density [43], [44]. 
Surabaya experiences temperatures from $24^{\circ} \mathrm{C}$ to $34^{\circ} \mathrm{C}$ according to literatures [45]. Within the study period from 2009 to 2017, the average temperatures in Surabaya were relatively steady and have very small variations throughout the year with the recorded minimum average temperature of $28^{\circ} \mathrm{C}$ and maximum of $35^{\circ} \mathrm{C}$, therefore it is not very meaningful to discuss the warmer and colder seasons. However, according to studies, temperature was a determinant of dengue outbreaks and was used in dengue prediction models in several countries [46]-[48].

Humidity also showed a similar trend with the DHF cases trend pattern, without highly marked fluctuations. The ranges of humidity is recorded as $65 \%$ to $85 \%$ in Surabaya [45]. While the average annual percentage of humidity in Surabaya is $74 \%$ with January being the most humid month and August as the least humid month, according to the "Weather-and-Climate" public website. There was a positive association between humidity and DHF incidence in studies [49], [50].

The monitoring of DHF cases were often done during the rainy season when the vector development is expected to occur at the highest rate [51], [52]. Based on the time series chart, the DHF incidence trend lags behind the rainfall trend. This indicates that the DHF cases were more likely to occur after an elevated rainfall event in Surabaya.

\subsection{Relationship between Climate Variability and Dengue Hemorrhagic Fever}

The results of this study revealed that climate variability is correlated with DHF incidence.

\subsubsection{Temperature and Dengue Hemorrhagic Fever}

The results showed that average temperature has a negative correlation with DHF incidence, which implies that when average temperature increases, DHF incidence decreases; and vice versa. Temperature influences the life cycle of the mosquitoes with an increment in the abundance of mosquitoes at more temperate regions compared to colder regions [53]. Ae. aegypti population dynamics are sensitive to changes in temperature, and the survival of the species increased in general when temperatures increased [53], [54].

Temperature affects the likelihood of midgut cell infection by the pathogen, and the ability for the pathogen to spread to be transmitted to a new host [55]. The warmer temperatures increase the metabolism of the mosquitoes, resulting in an increase of vector density when the number of breeding sites are still constant [56]. The warmer temperatures shorten the gonotrophic cycle of mosquitoes, reducing the extrinsic incubation period (EIP) and also the incubation period of dengue virus [35]. As the lifespan of Ae. aegypti is lengthened, there is an increased chance for mosquitoes to become infective, the biting rate increases, which causes the risk of transmission of dengue virus to susceptible hosts to increase [57], [58].

Ae. aegypti can tolerate a wider range of temperature compared to Ae. albopictus according to a study incorporating experimental models in the laboratory and in the field [59]. The thresholds of temperatures that affect the mortality of Ae. aegypti are $13.8^{\circ} \mathrm{C}$ which is the critical minimum temperature [60], and $35^{\circ} \mathrm{C}$ which is the maximum temperature threshold [35]. This indicates that the temperature has little effect on the mortality of mosquitoes, thus putting more emphasis on the shortened extrinsic incubation period due to warmer temperatures, which is the main cause of the lengthened lifespan of Ae.aegypti, causing the increased transmission of dengue virus.

Most studies have found that the increase in temperature increases the risk of dengue transmission. Teurlai et al. in New Caledonia concluded that by the end of the 21st century, the increase of temperature by approximately $3^{\circ} \mathrm{C}$ will double the mean incidence rates of dengue 
epidemics [59]; while $\mathrm{Wu}$ et al. in Taiwan found that the population is at risk for dengue fever transmission with every $1{ }^{\circ} \mathrm{C}$ increase of monthly average temperature by 1.95 times [61].

Despite most literatures stating a positive correlation between temperature and DHF incidence, there are literatures with similar findings to our study, finding a negative correlation between both variables. Kramer and Ebel found that adult mosquito survival rates were linked with lower temperatures [62] while Lambrechts et al. found that vector competence is reduced in Ae. aegypti for flaviviruses when the mean temperature fluctuations are above $18^{\circ} \mathrm{C}$, and increases when the mean temperature fluctuations are below $18^{\circ} \mathrm{C}$ [55]. Another study in Thailand has also found that seasonal variation of dengue virus transmission is inversely related to the magnitude of diurnal temperature ranges (DTR) of the region. According to their findings, a large DTR decreases mosquito survival, while a small DTR has a slightly more positive effect on mosquito survival [63]. These findings are supportive of our results, as Surabaya has a mean temperature fluctuation below $18^{\circ} \mathrm{C}$ within the study period, with an increased mosquito survival rate.

When average temperatures increase, the fecundity of Ae. aegypti reduces [64]. The high average temperatures with fluctuations was found to be detrimental for mosquito reproduction and it appears that there is an underlying physiological response of the mosquito to the daily variation in temperature affecting the developmental speed which is not observed under equivalent constant temperatures. This change is dependent on the change of the average temperature.

Therefore, this indicates that the survival of mosquitoes increase with a higher likelihood to be infected during moderate temperature fluctuations, than during large temperature fluctuations, which is consistent with the results of our study as Surabaya is a region with minimal temperature fluctuations.

Furthermore, regional climate phenomenon El Niño - Southern Oscillation (ENSO) - its El Niño phase, causes extensive droughts that increases temperatures, which in turn enhances the dengue virus replication and mosquito biting, forming an association with dengue epidemics [65]. The interaction of droughts and dengue transmission is more complex than the relationship between temperature and dengue transmission [25]

Another possible limitation of the study is from the lack of seasonal variation of temperature in Surabaya, making it more difficult to observe the influence of temperature almost throughout the year.

\subsubsection{Rainfall and Dengue Hemorrhagic Fever}

The results showed that rainfall is positively correlated to DHF incidence. This implies that as rainfall increases, DHF incidence increase. Increased rainfall increases the potential breeding sites of Aedes mosquitoes [58], which leads to an increased propagation of mosquitoes, increasing vector density [11], and thus increasing the risk of transmission of dengue virus. However, this relationship is not clear because the Ae. aegypti mosquito species, which is responsible for the dengue virus transmission in Indonesia, is a domestic species that breeds primarily in indoor settings [66].

Ae. aegypti is less likely to be influenced by rainfall to transmit outbreaks as it breeds indoor primarily compared to Ae. albopictus that breeds in outdoor habitats [67]. However, there still lies a possibility that the domestication process of mosquitoes may increase its competence to transmit human virus [68], because the oviposition behavior of vectors in different environments still remain unknown [69]. This theory supports the result of this study which indicated only a moderately 
significant correlation between rainfall and DHF cases, because non-climatic factors also play a big role in the increasing abundance of breeding sites.

The non-climatic factors has a potential to increase breeding sites due to the multifactorial nature of dengue virus transmission [70]. The non-climatic factors include human behavior by their water storage practices, rapid urbanization which may result in substandard housing, and the deterioration of the water, sewers and waste management system [9]. The clogged pipes, or improper water storage methods may cause rainwater collection, increasing potential breeding sites, and increase the risk of dengue transmission.

In this study, there was an increased incidence of DHF cases from the months March to May. This corresponds to the rainfall seasonality pattern in Surabaya, East Java, Indonesia where the wet season lies from October to April, where heaviest rainfall occurs towards the end of the wet season in April. From a study in São Paulo, Brazil, there was an increment of dengue cases as a result from elevated rainfall in previous months [71]. The incidence rate is presented in a seasonal trend, showing a similar pattern between rainfall and the dengue incidence in several other studies [72], [73], indicating a consistency in the results of this study.

Regional climate phenomenon which is the El Niño-Southern Oscillation (ENSO) may affect the rainfall of the study area. El Niño events especially has a positive association with the increased dengue cases in Ecuador and Brazil [74], [75]. The stronger El Niño events in recent decades are associated with increased droughts in tropical lands which includes Indonesia [76]. During droughts, human response to collect water increases, thus increasing the potential breeding sites of mosquitoes, leading to the increased risk of dengue transmission. For example, studies found several countries that store water while facing droughts are found to experience dengue epidemics such as in Barbados, Brazil, Thailand and Australia [77], [78].

The study area Surabaya, East Java, Indonesia is a region with dry seasons and rainy seasons. Flooding occurs frequently during the rainy season while droughts sometimes occur during the dry seasons, which both might increase the transmission probability of dengue fever. Flooding may increase the vector densities and increase dengue virus transmission rate [79]-[81]. This is because more breeding conditions of Aedes mosquitoes are formed when the increased water levels during floods recede [82].

\subsubsection{Humidity and Dengue Hemorrhagic Fever}

The results from this study showed a positive correlation between humidity and DHF incidence. This implies that when humidity increases, there is a bigger magnitude and higher incidence of DHF cases in Surabaya. The rising humidity influences the feeding pattern of Aedes mosquitoes, thus increasing the survival and lifespan of the mosquitoes [58]. Humidity was also found to be the most reliable indicator in dengue incidence models aside from the other weather parameters, due to its more stable impact on the dengue incidence in the model in Taiwan [50].

This finding is consistent with the result of this study, because humidity is found to have the highest correlation coefficient with DHF cases compared to the other to climate variables (temperature and rainfall). However, there is cautioning to interpret the results of this climate variable due to its biological causation from rainfall and temperature [83]. This is because the humidity is influenced by the rainfall and temperature of a region. 
Several studies also found a significant correlation between humidity and dengue cases with seasonal periodicities [48], [83]. Humidity is incorporated into models to chart the geographical spread of dengue fever transmission and human population projections [84].

\subsection{Limitations of Study}

The limitations of this study included the unconfirmed nature of the DHF cases and the underreported dengue cases. This is because the official total number of DHF cases reported by the Surabaya City Health Office were based on clinical criteria only, without serological confirmation tests. The underreported dengue cases consist of the asymptomatic cases which were not recorded consistently leading to estimations that the total asymptomatic cases could be higher than the reported cases.

Underreported cases may increase during peak tourism period when tourists with asymptomatic dengue infection infect mosquitoes at Surabaya and plants a greater threat of dengue outbreak in the future. Therefore, there may lie an inaccuracy in the reporting of DHF cases which may provide misleading results in this study. However, the probability of a big cluster of misdiagnosed cases is very low due to the distinct clinical features of dengue infection.

The total number of DHF cases reported remained at an underestimated value in many nations worldwide. Limited communication and logistic facilities in rural areas of Surabaya, contributing to the more passive surveillance effort, hampered consistent and complete DHF reports.

Another limitation of this study was the lack of mosquito data. The spatial distribution and abundance of mosquitoes in Surabaya was not considered in this study. Theoretically, Ae. aegypti is distributed more around locations with a denser population and urbanization. Furthermore, the virulence of the mosquitoes in Surabaya was not factored into this study. The vector ecology and their density dynamics in Surabaya should be addressed in this study to ensure a more thorough study on the complex nature behind climate variability and the increase of DHF incidence. This will assist in the future planning of strategic surveillance of public health diseases and disease control.

Furthermore, the role of socioeconomic development that may affect dengue virus infection and transmission, epidemiological reporting of dengue cases and dengue control may be assessed and addressed in future studies as factors that may alter the results of the research.

Other determinants of the DHF incidence trend in this study which were not studied and addressed were the non-climatic factors such as vector control capacity and the surveillance programs, drainage cleaning programs in Surabaya, herd immunity for DENV, increased human mobility, altered human-host interaction, demographic changes (population density, urbanization, modern transportation), environmental change and regional climate phenomenon such as ENSO.

\subsection{Implications of Research}

Research about the linkages between climate and health has been increasing worldwide, but currently there is a lack of conclusive data on the correlation of both variables in Surabaya. Dengue hemorrhagic fever is still hyperendemic in Indonesia even though the rate of DHF incidence and CFR has dropped recently according to our results. In addition, to date, research in Surabaya has mainly concentrated on the identification, characterization and quantification of the endemicity of DHF incidence but not on the linkage of climatic factors with DHF incidence.

Previous studies focused more on the clinical, virologic and epidemiological aspects of dengue transmission in Surabaya [85], [86], rather than the spatial and transmission heterogeneity of DHF 
based on the weather predictors of Surabaya, East Java, Indonesia. This study focused more on the correlation analysis of the climatic variables and DHF incidence of the whole Surabaya to investigate the potential effect of climate variability on DHF occurrence. The findings of this study will provide new evidence on the relationship between climate variability and DHF in Surabaya in recent years and may aid in the development of disease prediction models in the future.

Furthermore, current studies on the latest trends and incidence of DHF in Surabaya are scarce. There are very limited studies done on the correlation between climate variability and DHF incidence in Surabaya. Due to this, the link between climate variability and DHF incidence in Surabaya was not well established. The results of this study demonstrated the current trends and incidence of DHF in Surabaya. It implicates the Indonesian government and public health officials to integrate climate variability into a timely dengue prediction model to be able to minimize the spread of dengue disease after the occurrence of an elevated rainfall event.

The information from this study may provide basic knowledge to develop an early warning system (EWS) regarding dengue transmission as currently, the dengue surveillance programs in Indonesia are largely passive while several South East Asia (SEA) countries including Malaysia and Singapore have active surveillance programs to monitor the risk of the spawning of a dengue epidemic.

This research should be able to guide the process to develop proper tools and provide informed choices to improve the health and lives of the citizens of Surabaya, East Java, Indonesia and of the world.

\section{Conclusions}

From our findings, it is concluded there is a significant correlation between climate variability and DHF incidence in Surabaya, East Java, Indonesia from 2009 to 2017. The findings from this study may be useful to continue on research necessary for the development of the dengue control programs. The application of these findings into public health measure designs may help mitigate the transmission risk of dengue disease.

Supplementary Materials: (Attached with submission)

Author Contributions: Conceptualization, Sandra Choi Ning Tang; Data curation, Sandra Choi Ning Tang; Formal analysis, Sandra Choi Ning Tang; Investigation, Sandra Choi Ning Tang; Methodology, Sandra Choi Ning Tang; Project administration, Sandra Choi Ning Tang, Musofa Rusli and Pudji Lestari; Resources, Sandra Choi Ning Tang, Musofa Rusli and Pudji Lestari; Software, Sandra Choi Ning Tang and Pudji Lestari; Supervision, Musofa Rusli and Pudji Lestari; Validation, Sandra Choi Ning Tang, Musofa Rusli and Pudji Lestari; Visualization, Sandra Choi Ning Tang; Writing - original draft, Sandra Choi Ning Tang; Writing - review \& editing, Sandra Choi Ning Tang, Musofa Rusli and Pudji Lestari.

Funding: This research received no external funding.

Conflicts of Interest: The authors declare no conflict of interest.

\section{References}

[1] WHO, Comprehensive Guidelines for Prevention and Control of Dengue and Dengue Haemorrhagic Fever, no. 1. SEARO Technical Publication, 2011.

[2] M. R. Karyanti, C. S. P. M. Uiterwaal, R. Kusriastuti, S. R. Hadinegoro, M. M. Rovers, H. Heesterbeek, A. W. Hoes, and P. Bruijning-Verhagen, "The Changing Incidence of Dengue Haemorrhagic Fever in Indonesia: A 45-year Registry-Based Analysis," BMC Infect. Dis., vol. 14, no. 1, p. 412, 2014. 
East Java Province Health Office, 2012.

[4] C. P. Simmons, J. J. Farrar, N. van Vinh Chau, and B. Wills, “Dengue,” N. Engl. J. Med., vol. 366, no. 15, pp. 1423-1432, Apr. 2012.

[5] R. Akhtar, "Health Adaptation Scenario and Dengue Fever Vulnerability Assessment," in Climate Change and Human Health Scenario in South and Southeast Asia, Rais Akhtar, Ed. Springer, 2016, p. 290.

[6] L. Lambrechts, T. W. Scott, and D. J. Gubler, “Consequences of The Expanding Global Distribution of Aedes Albopictus for Dengue Virus Transmission," PLoS Negl. Trop. Dis., vol. 4, no. 5, 2010.

[7] D. Beasley and A. Barrett, "The Infectious Agent," in The Infectious Agent, P. G and H. SL, Eds. Dengue. Vol. 5. Imperial College Press; Covent Garden, London, UK, 2008, pp. 29-73.

[8] WHO, “Dengue: Guidelines for Diagnosis, Treatment, Prevention, and Control," Spec. Program. Res. Train. Trop. Dis., p. 147, 2009.

[9] D. J. Gubler, "Dengue and Dengue Hemorrhagic Fever," Clin. Microbiol. Rev., vol. 11, no. 3, pp. 480-496, 1998.

[10] P. R. Epstein, “Climate Change and Emerging Infectious Diseases," Microbes Infect., vol. 3, no. 9, pp. 747754, Jul. 2001.

[11] L. Xu, L. C. Stige, K. Chan, J. Zhou, J. Yang, S. Sang, M. Wang, and Z. Yang, “Climate Variation Drives Dengue Dynamics," Proc. Natl. Acad. Sci. U. S. A., vol. 114, no. 1, pp. 113-118, 2017.

[12] S. Naish, P. Dale, J. S. Mackenzie, J. McBride, K. Mengersen, and S. Tong, “Climate Change and Dengue: A Critical and Systematic Review of Quantitative Modelling Approaches," BMC Infect. Dis., vol. 14, no. 1, p. 167, 2014.

[13] L. Regis, A. M. Monteiro, M. A. V. De Melo-Santos, J. C. Silveira, A. F. Furtado, R. V. Acioli, G. M. Santos, M. Nakazawa, M. S. Carvalho, P. J. Ribeiro, and W. V. De Souza, “Developing New Approaches for Detecting and Preventing Aedes Aegypti Population Outbreaks: Basis for Surveillance, Alert and Control System," Mem. Inst. Oswaldo Cruz, vol. 103, no. 1, pp. 50-59, 2008.

[14] E. A. P. D. A. Costa, E. M. D. M. Santos, J. C. Correia, and C. M. R. De Albuquerque, “Impact of Small Variations in Temperature and Humidity on The Reproductive Activity and Survival of Aedes aegypti (Diptera, Culicidae)," Rev. Bras. Entomol., vol. 54, no. 3, pp. 488-493, 2010.

[15] J. C. Semenza and B. Menne, "Climate Change and Infectious Diseases in Europe," Lancet Infect. Dis., vol. 9, no. 6, pp. 365-375, 2009.

[16] J. Liu-Helmersson, H. Stenlund, A. Wilder-Smith, and J. Rocklöv, “Vectorial Capacity of Aedes aegypti: Effects of Temperature and Implications for Global Dengue Epidemic Potential," PLoS One, vol. 9, no. 3, p. 10, 2014.

[17] S. Hales, S. Kovats, S. Lloyd, and D. Campbell-Lendrum, "Quantitative Risk Assessment of The Effects of Climate Change on Selected Causes of Death , 2030s and 2050s," Risk Assessment. I.World Heal. Organ., p. 128, 2014.

[18] R. Yudhastuti, P. Satyabakti, and H. Basuki, “Climate Conditions, Larvae Free Number, DHF Incidence in Surabaya Indonesia," J. US-China Public Adm., vol. 10, no. 11, pp. 1043-1049, 2013.

[19] Ministry of Health Republic of Indonesia, Indonesian Health Profile. 2017.

[20] Sumarmo, “Dengue Haemorrhagic Fever in Indonesia,” Southeast Asian J. Trop. Med. Public Health, vol. 18, no. 3, pp. 269-74, Sep. 1987.

[21] C. Prasittisuk, A. G. Andjaparidze, and V. Kumar, “Current Status of Dengue/Dengue Haemorrhagic Fever in WHO South-East Asia Region," 1998.

[22] R. Kusriastuti and S. Sutomo, “Evolution of Dengue Prevention and Control Programme in Indonesia," 2005. 
[23] R. Tosepu, D. Effendy, and H. Bahar, “Indonesian Strategy in Reducing Aedes aegypty Diseases in ASEAN Economic Community Era," Int. J. Res. Med. Sci., vol. 3, no. 7, pp. 1578-1582, Jan. 2015.

[24] K. Ahmad, “Dengue Death Toll Rises in Indonesia," Lancet, vol. 363, no. 9413, p. 956, Mar. 2004.

[25] M. Tipayamongkholgul, C.-T. Fang, S. Klinchan, C.-M. Liu, and C.-C. King, “Effects of The El NiñoSouthern Oscillation on Dengue Epidemics in Thailand, 1996-2005," BMC Public Health, vol. 9, p. 422, Nov. 2009.

[26] D. O. Fuller, A. Troyo, and J. C. Beier, “El Niño Southern Oscillation and Vegetation Dynamics as Predictors of Dengue Fever Cases in Costa Rica," Environ. Res. Lett., vol. 4, pp. 140111-140118, Mar. 2009.

[27] S. C. Lewis and A. N. Legrande, "Stability of ENSO and Its Tropical Pacific Teleconnections Over The Last Millennium," Clim. Past, vol. 11, pp. 1347-1360, 2015.

[28] M. F. Vincenti-Gonzalez, A. Tami, E. F. Lizarazo, and M. E. Grillet, “ENSO-Driven Climate Variability Promotes Periodic Major Outbreaks of Dengue in Venezuela," Sci. Rep., vol. 8, no. 1, p. 5727, Dec. 2018.

[29] M. L. Khandekar, “2010 Pakistan Floods: Climate Change or Natural Variability?,” Can. Meteorol. Oceanogr. Soc., vol. 38, no. 5, pp. 165-167, 2010.

[30] P. J. Ward, B. Jongman, M. Kummu, M. D. Dettinger, F. C. Sperna Weiland, and H. C. Winsemius, “Strong Influence of El Niño Southern Oscillation on Flood Risk Around The World," Proc. Natl. Acad. Sci. U. S. A., vol. 111, no. 44, pp. 15659-64, Nov. 2014.

[31] ESCAP, RIMES, and UNDP, “Assessment of El Niño-Associated Risks: The Step-Wise Process,” 2016.

[32] K. Kuhn, D.Campbell-Lendrum, A. Haines, and J. Cox, "Using Climate to Predict Infectious Disease Epidemics," 2005.

[33] J. Liang, X.-Q. Yang, D.-Z. Sun, J. Liang, X.-Q. Yang, and D.-Z. Sun, “The Effect of ENSO Events on The Tropical Pacific Mean Climate: Insights From An Analytical Model," J. Clim., vol. 25, no. 21, pp. 75907606, Nov. 2012.

[34] M. A. Cane, “The Evolution of El Niño, Past and Future,” Earth Planet. Sci. Lett., vol. 230, pp. 227-440, 2005.

[35] R. E. Whitmire, D. S. Burke, A. Nisalak, B. A. Harrison, and D. M. Watts, “Effect of Temperature on the Vector Efficiency of Aedes aegypti for Dengue 2 Virus," Am. J. Trop. Med. Hyg., vol. 36, no. 1, pp. 143152, Jan. 1987.

[36] S. R. Mutheneni, A. P. Morse, C. Caminade, and S. M. Upadhyayula, “Dengue Burden in India: Recent Trends and Importance of Climatic Parameters," Emerg. Microbes Infect., vol. 6, no. 8, p. e70, Aug. 2017.

[37] J. Sun, L. Lu, H. Wu, J. Yang, L. Xu, S. Sang, and Q. Liu, “Epidemiological Trends of Dengue in Mainland China, 2005-2015," Int. J. Infect. Dis., vol. 57, pp. 86-91, 2017.

[38] J. Rajarethinam, L.-W. Ang, J. Ong, J. Ycasas, H. C. Hapuarachchi, G. Yap, C.-S. Chong, Y.-L. Lai, J. Cutter, D. Ho, V. Lee, and L.-C. Ng, “Dengue in Singapore from 2004 to 2016: Cyclical Epidemic Patterns Dominated by Serotypes 1 and 2.," Am. J. Trop. Med. Hyg., vol. 99, no. 1, pp. 204-210, Jul. 2018.

[39] A. H. Mohd-Zaki, J. Brett, E. Ismail, and M. L'Azou, “Epidemiology of Dengue Disease in Malaysia (2000-2012): A Systematic Literature Review.," PLoS Negl. Trop. Dis., vol. 8, no. 11, p. e3159, 2014.

[40] D. J. Gubler, "How Effectively is Epidemiological Surveillance Used for Dengue Programme Planning and Epidemic Response?," 2002.

[41] S. I. Hernández-Gaytán, F. J. Díaz-Vásquez, L. G. Duran-Arenas, M. López Cervantes, and S. J. Rothenberg, “20 Years Spatial-Temporal Analysis of Dengue Fever and Hemorrhagic Fever in Mexico,” Arch. Med. Res., vol. 48, no. 7, pp. 653-662, Oct. 2017.

[42] E. S. Paixão, M. da C. N. Costa, L. C. Rodrigues, D. Rasella, L. L. Cardim, A. C. Brasileiro, M. G. L. C. Teixeira, E. S. Paixão, M. da C. N. Costa, L. C. Rodrigues, D. Rasella, L. L. Cardim, A. C. Brasileiro, and 
M. G. L. C. Teixeira, “Trends and Factors Associated with Dengue Mortality and Fatality in Brazil,” Rev. Soc. Bras. Med. Trop., vol. 48, no. 4, pp. 399-405, Aug. 2015.

[43] F. D. Silva, A. M. dos Santos, R. da G. C. F. Corrêa, and A. de J. M. Caldas, “Temporal Relationship Between Rainfall, Temperature and Occurrence of Dengue Cases in São Luís, Maranhão, Brazil," Cien. Saude Colet., vol. 21, no. 2, pp. 641-646, Feb. 2016.

[44] G. L. S. Su, “Correlation of Climatic Factors and Dengue Incidence in Metro Manila, Philippines.," Ambio, vol. 37, no. 4, pp. 292-4, Jun. 2008.

[45] United Nations, “Urban Solid Waste Management: Surabaya, Indonesia," in Cities and Sustainable Developement: Lessons and Experiences from Asia and the Pacific, New York: United Nations Publication, 2003, pp. 48-56.

[46] S. Thammapalo, V. Chongsuwiwatwong, D. McNeil, and A. Geater, "The Climatic Factors Influencing The Occurrence of Dengue Hemorrhagic Fever in Thailand," Southeast Asian J. Trop. Med. Public Health, vol. 36, no. 1, pp. 191-6, Jan. 2005.

[47] R. Lowe, T. C. Bailey, D. B. Stephenson, R. J. Graham, C. A. S. Coelho, M. S. Carvalho, and C. Barcellos, "Spatio-Temporal Modelling of Climate-Sensitive Disease Risk: Towards An Early Warning System for Dengue in Brazil," Comput. Geosci., vol. 37, pp. 371-381, 2011.

[48] E. Descloux, M. Mangeas, C. E. Menkes, M. Lengaigne, A. Leroy, T. Tehei, L. Guillaumot, M. Teurlai, A.C. Gourinat, J. Benzler, A. Pfannstiel, J.-P. Grangeon, N. Degallier, and X. De Lamballerie, “ClimateBased Models for Understanding and Forecasting Dengue Epidemics," PLoS Negl. Trop. Dis., vol. 6, no. 2, p. e1470, Feb. 2012.

[49] X. Wu, L. Lang, W. Ma, T. Song, M. Kang, J. He, Y. Zhang, L. Lu, H. Lin, and L. Ling, “Non-Linear Effects of Mean Temperature and Relative Humidity on Dengue Incidence in Guangzhou, China," Sci. Total Environ., vol. 628-629, pp. 766-771, Jul. 2018.

[50] H.-Y. Xu, X. Fu, L. K. H. Lee, S. Ma, K. T. Goh, J. Wong, M. S. Habibullah, G. K. K. Lee, T. K. Lim, P. A. Tambyah, C. L. Lim, and L. C. Ng, "Statistical Modeling Reveals the Effect of Absolute Humidity on Dengue in Singapore," PLoS Negl. Trop. Dis., vol. 8, no. 5, p. e2805, May 2014.

[51] L. Thi Diem Phuong, T. Thi Tuyet Hanh, and V. Sinh Nam, “Climate Variability and Dengue Hemorrhagic Fever in Ba Tri District, Ben Tre Province, Vietnam during 2004-2014," AIMS Public Heal., vol. 3, no. 4, pp. 769-780, 2016.

[52] J. Chompoosri, U. Thavara, A. Tawatsin, S. Anantapreecha, and P. Siriyasatien, “Seasonal Monitoring of Dengue Infection in Aedes aegypti and Serological Feature of Patients with Suspected Dengue in 4 Central Provinces of Thailand," 2012.

[53] K. Ng, L. F. Chaves, K. Tsai, and T. Chuang, “Abundance in A Dengue Transmission Hotspot , Compared to A Coldspot, Within Kaohsiung," Insects, vol. 9, no. 3, pp. 1-16, 2018.

[54] M. G. Grech, P. D. Sartor, W. R. Almirón, and F. F. Ludueña-Almeida, “Effect of Temperature on Life History Traits During Immature Development of Aedes aegypti and Culex quinquefasciatus (Diptera: Culicidae) from Córdoba City, Argentina," Acta Trop., vol. 146, pp. 1-6, Jun. 2015.

[55] L. Lambrechts, K. P. Paaijmans, T. Fansiri, L. B. Carrington, L. D. Kramer, M. B. Thomas, and T. W. Scott, "Impact of Daily Temperature Fluctuations on Dengue Virus Transmission by Aedes aegypti.," Proc. Natl. Acad. Sci. U. S. A., vol. 108, no. 18, pp. 7460-5, May 2011.

[56] O. J. Brady, M. A. Johansson, C. A. Guerra, S. Bhatt, N. Golding, D. M. Pigott, H. Delatte, M. G. Grech, P. T. Leisnham, R. Maciel-de-Freitas, L. M. Styer, D. L. Smith, T. W. Scott, P. W. Gething, and S. I. Hay, "Modelling Adult Aedes aegypti and Aedes albopictus Survival at Different Temperatures in Laboratory and Field Settings," Parasit. Vectors, vol. 6, no. 1, p. 351, 2013. 
[57] B. W. Alto and D. Bettinardi, “Temperature and Dengue Virus Infection in Mosquitoes: Independent Effects on the Immature and Adult Stages," Am. J. Trop. Med. Hyg., vol. 88, no. 3, pp. 497-505, Mar. 2013.

[58] D. A. Focks, D. G. Haile, E. Daniels, and G. A. Mount, “Dynamic Life Table Model for Aedes aegypti (Diptera: Culicidae): Analysis Of The Literature and Model Development," J. Med. Entomol., vol. 30, no. 6, pp. 1003-17, Nov. 1993.

[59] M. Teurlai, C. E. Menkès, V. Cavarero, N. Degallier, E. Descloux, J.-P. Grangeon, L. Guillaumot, T. Libourel, P. S. Lucio, F. Mathieu-Daudé, and M. Mangeas, "Socio-Economic and Climate Factors Associated With Dengue Fever Spatial Heterogeneity: A Worked Example in New Caledonia.," PLoS Negl. Trop. Dis., vol. 9, no. 12, p. e0004211, Dec. 2015.

[60] P.-J. Tsai, T.-H. Lin, H.-J. Teng, and H.-C. Yeh, “Critical Low Temperature For The Survival of Aedes aegypti in Taiwan," Parasit. Vectors, vol. 11, no. 1, p. 22, 2018.

[61] P. C. Wu, J. G. Lay, H. R. Guo, C. Y. Lin, S. C. Lung, and H. J. Su, “Higher Temperature and Urbanization Affect The Spatial Patterns of Dengue Fever Transmission in Subtropical Taiwan," Sci. Total Environ., vol. 407, no. 7, pp. 2224-2233, 2009.

[62] L. D. Kramer and G. D. Ebel, "Dynamics of Flavivirus Infection in Mosquitoes.," Adv. Virus Res., vol. 60, pp. 187-232, 2003.

[63] L. B. Carrington, S. N. Seifert, N. H. Willits, L. Lambrechts, and T. W. Scott, "Large Diurnal Temperature Fluctuations Negatively Influence Aedes aegypti (Diptera: Culicidae) Life-History Traits," J. Med. Entomol., vol. 50, no. 1, pp. 43-51, Jan. 2013.

[64] L. B. Carrington, M. V. Armijos, L. Lambrechts, C. M. Barker, and T. W. Scott, “Effects of Fluctuating Daily Temperatures at Critical Thermal Extremes on Aedes aegypti Life-History Traits," PLoS One, vol. 8, no. 3, p. e58824, Mar. 2013.

[65] D. M. Watts, D. S. Burke, B. A. Harrison, R. E. Whitmire, and A. Nisalak, "Effect of Temperature on The Vector Efficiency of Aedes aegypti for Dengue 2 Virus," Am. J. Trop. Med. Hyg., vol. 36, no. 1, pp. 14352, Jan. 1987.

[66] M. Trpis and W. Hausermann, “Demonstration of Differential Domesticity of Aedes aegypti (L.) (Diptera, Culicidae) in Africa By Mark-Release-Recapture," Bull. Entomol. Res., vol. 65, no. 02, p. 199, Jun. 1975.

[67] I. Banks, P. T. Brey, N. Hill, A. Kaye, K. Vongphayloth, P. Khammanithong, S. W. Lindsay, S. Kaul, A. Hiscox, M. Piffer, and P. Sananikhom, “Risk Factors for the Presence of Aedes aegypti and Aedes albopictus in Domestic Water-Holding Containers in Areas Impacted by the Nam Theun 2 Hydroelectric Project, Laos," Am. J. Trop. Med. Hyg., vol. 88, no. 6, pp. 1070-1078, Jun. 2013.

[68] J. R. Powell and W. J. Tabachnick, "History of Domestication and Spread of Aedes aegypti--A Review," Mem. Inst. Oswaldo Cruz, vol. 108 Suppl, no. Suppl 1, pp. 11-7, 2013.

[69] F. V. S. de Abreu, M. M. Morais, S. P. Ribeiro, and Á. E. Eiras, “Influence of Breeding Site Availability on The Oviposition Behaviour of Aedes aegypti.," Mem. Inst. Oswaldo Cruz, vol. 110, no. 5, pp. 669-76, Aug. 2015.

[70] D. J. Gubler, “Dengue, Urbanization and Globalization: The Unholy Trinity of the 21(st) Century.," Trop. Med. Health, vol. 39, no. 4 Suppl, pp. 3-11, Dec. 2011.

[71] A. C. Ferreira, F. Chiaravalloti Neto, A. Mondini, and A. Mondini, “Dengue in Araraquara, State of São Paulo: Epidemiology, Climate and Aedes aegypti Infestation.," Rev. Saude Publica, vol. 52, p. 18, 2018.

[72] M. R. Dibo, A. P. Chierotti, M. S. Ferrari, A. L. Mendonça, and F. Chiaravalloti Neto, "Study of The Relationship Between Aedes (Stegomyia) aegypti Egg and Adult Densities, Dengue Fever and Climate in Mirassol, State of São Paulo, Brazil.," Mem. Inst. Oswaldo Cruz, vol. 103, no. 6, pp. 554-60, Sep. 2008. 
[73] M. A. Johansson, F. Dominici, and G. E. Glass, “Local and Global Effects of Climate on Dengue Transmission in Puerto Rico," PLoS Negl. Trop. Dis., vol. 3, no. 2, pp. 1-5, 2009.

[74] R. Lowe and A. M. Stewart-Ibarra, “Climate and Non-Climate Drivers of Dengue Epidemics in Southern Coastal Ecuador," Am. J. Trop. Med. Hyg., vol. 88, no. 5, pp. 971-981, May 2013.

[75] A. Nava, J. S. Shimabukuro, A. A. Chmura, and S. L. B. Luz, "The Impact of Global Environmental Changes on Infectious Disease Emergence with a Focus on Risks for Brazil," Inst. Lab. Anim. Res. J., vol. 58, no. 3, pp. 393-400, Dec. 2017.

[76] B. Lyon and A. G. Barnston, "ENSO and the Spatial Extent of Interannual Precipitation Extremes in Tropical Land Areas," 2004.

[77] D. Parker and D. Holman, “Event History Analysis of Dengue Fever Epidemic and Inter-Epidemic Spells in Barbados, Brazil, and Thailand.," Int. J. Infect. Dis., vol. 16, no. 11, pp. e793-8, Nov. 2012.

[78] B. J. Trewin, B. H. Kay, J. M. Darbro, and T. P. Hurst, "Increased Container-Breeding Mosquito Risk Owing to Drought-Induced Changes in Water Harvesting and Storage in Brisbane, Australia," Int. Health, vol. 5, no. 4, pp. 251-258, Dec. 2013.

[79] A. Jiménez-Sastré, X. Boldo-León, H. Priego-Álvarez, E. Quevedo-Tejero, and M. A. Zavala-González, “Geographic Distribution of Dengue Fever Cases in Flooded Zones from Villahermosa, Tabasco, in 2010," Rev. Chil. Infectología, vol. 29, no. 1, pp. 32-36, Feb. 2012.

[80] A. Anyamba, J. L. Small, S. C. Britch, C. J. Tucker, E. W. Pak, C. A. Reynolds, J. Crutchfield, and K. J. Linthicum, "Recent Weather Extremes and Impacts on Agricultural Production and Vector-Borne Disease Outbreak Patterns," PLoS One, vol. 9, no. 3, p. e92538, Mar. 2014.

[81] L. Brown and V. Murray, "Examining The Telationship Between Infectious Diseases and Flooding in Europe: A Systematic Literature Review and Summary of Possible Public Health Interventions," Disaster Heal., vol. 1, no. 2, pp. 117-127, 2013.

[82] M. Hashizume, A. M. Dewan, T. Sunahara, M. Z. Rahman, and T. Yamamoto, “Hydroclimatological Variability and Dengue Transmission in Dhaka, Bangladesh: A Time-Series Study," BMC Infect. Dis., vol. 12, no. 1, p. 98, Dec. 2012.

[83] T. T. T. Do, P. Martens, N. H. Luu, P. Wright, and M. Choisy, “Climatic-Driven Seasonality of Emerging Dengue Fever in Hanoi, Vietnam," BMC Public Health, vol. 14, no. 1, p. 1078, Dec. 2014.

[84] S. Hales, N. de Wet, J. Maindonald, and A. Woodward, "Potential Effect of Population and Climate Changes on Global Distribution of Dengue Fever: An Empirical Model," Lancet, vol. 360, no. 9336, pp. 830-834, Sep. 2002.

[85] B. Yohan, P. Wardhani, H. Trimarsanto, A. Aryati, and R. T. Sasmono, “Genomic Analysis of Dengue Virus Serotype 1 (DENV-1) Genotypes from Surabaya, Indonesia," Virus Genes, vol. 54, no. 3, pp. 461465, Jun. 2018.

[86] P. Wardhani, A. Aryati, B. Yohan, H. Trimarsanto, T. Y. Setianingsih, D. Puspitasari, M. V. Arfijanto, B. Bramantono, S. Suharto, and R. T. Sasmono, "Clinical and Virological Characteristics of Dengue in Surabaya, Indonesia," PLoS One, vol. 12, no. 6, p. 14, Jun. 2017. 